\title{
DBC1 promotes anoikis resistance of gastric cancer cells by regulating NF- $\mathrm{KB}$ activity
}

\author{
YONGWEI HUAN ${ }^{1,2^{*}}$, DEPING WU ${ }^{3 *}$, DAYONG ZHOU ${ }^{1}$, BO SUN $^{1}$ and GUOXIN LI $^{2}$ \\ ${ }^{1}$ Department of General Surgery, the 82nd Hospital of the PLA, Huai'an; \\ ${ }^{2}$ Department of General Surgery, Nanfang Hospital of Southern Medical University, Guangzhou; \\ ${ }^{3}$ Department of Laboratory Medicine, the 82nd Hospital of the PLA, Huai'an, P.R. China
}

Received March 2, 2015; Accepted April 6, 2015

DOI: $10.3892 / o r .2015 .4007$

\begin{abstract}
Deleted in breast cancer 1 (DBC1) has been known to be overexpressed and serves as a poor prognostic indicator of several human cancers. In this study, we examined DBC1 expression in a total of 142 gastric cancer tissues by immunohistochemistry and revealed that DBC1 was overexpressed in gastric cancer and significantly associated with TNM stage and lymph node metastasis. The in vitro experiments showed that DBC1 expression correlated with the ability of anoikis resistance in gastric cancer cells, which has been defined as critical to metastasis. Furthermore, the results showed that the IKK- $\beta / N F-\kappa B$ signaling pathway was involved in the regulation of anoikis resistance by $\mathrm{DBC} 1$ in gastric cancer cells. Taken together, the results indicated that $\mathrm{DBC} 1$ promotes anoikis resistance in gastric cancer cells by regulating $\mathrm{NF}-\kappa \mathrm{B}$ activity and may thus be a new therapeutic target for preventing potential metastasis.
\end{abstract}

\section{Introduction}

Although much progress has been made in early diagnosis, surgery, chemotherapy and targeted drugs, gastric cancer remains the second most common cause of cancer-associated mortality worldwide $(1,2)$.Metastasis is a major clinical obstacle for the treatment of gastric cancer and therefore, a better understanding of the gene regulation involved in the development of metastasis may lead to therapeutic improvements for gastric cancer patients.

Metastasis is a multistep process including the dissociation of cancer cells from primary sites, survival in the vascular

Correspondence to: Professor Guoxin Li, Department of General Surgery, Nanfang Hospital of Southern Medical University, 1838 North Guangzhou Road, Guangzhou 510515, P.R. China

E-mail: liguoxin201211@163.com

*Contributed equally

Key words: deleted in breast cancer 1, anoikis, metastasis, NF- $\kappa \mathrm{B}$, gastric cancer system, and proliferation in distant target organs (3). As a barrier to metastasis, cells normally undergo an apoptotic process known as 'anoikis', a form of cell death due to loss of contact with the extracellular matrix or neighboring cells (3-5). However, a subset of cancer cells acquires the ability to resist anoikis and thus survives after detachment from the primary sites and travels through the circulatory and lymphatic systems to disseminate throughout the body (3-5). Recently, identification of the factors and mechanisms that control anoikis has become a high priority in cancer cell biology and developmental therapeutics.

Deleted in breast cancer 1 (DBC1) is a nuclear protein encoded by a gene on $8 \mathrm{p} 21$ that was originally believed to reside within a deleted region in breast cancer, a deletion assignment that was subsequently found to be inaccurate $(6,7)$. DBC1 overexpression has been observed in colorectal, esophageal and breast cancer, where its overexpression correlates, in some cases, with poor prognosis (8-11). Currently, the molecular and cell functions of $\mathrm{DBC} 1$ are being extensively investigated to reveal its precise physiological role. The endogenous $\mathrm{DBC} 1$ is a nuclear protein and the amino-terminus of $\mathrm{DBC} 1$ has been shown to be a protein-interaction surface. Additionally, DBC1 serves as a transcriptional factor that represses the transcriptional activation function, such as SIRT1, BRCA1 and estrogen receptor $\beta$ (12-15). However, DBC1 was recently reported to interact with IKK- $\beta$, stimulate its kinase activity, and thus promote $\mathrm{NF}-\kappa \mathrm{B}$ transcriptional activity through the phosphorylation of relA serine-536, by which, DBC1 suppressed anoikis in normal epithelial and breast cancer cell lines (7).

In this study, we performed immunohistochemical staining to examine the prevalence and prognostic impact of DBC1 expression in gastric cancer patients. Moreover, we investigated the possible role and mechanism of $\mathrm{DBC} 1$ in the regulation of anoikis in gastric cancer cells and demonstrated that $\mathrm{DBC} 1$ promoted anoikis resistance of gastric cancer cells by regulating $\mathrm{NF}-\kappa \mathrm{B}$ activity.

\section{Materials and methods}

Patients and samples. A total of 142 cases of gastric adenocarcinoma patients who had radical gastrectomy at the $82 \mathrm{nd}$ hospital of the PLA between January 2008 and December 2009 were included in the present study. None of the patients 
received chemotherapy prior to surgery and were followed-up by a review of medical records and telephone calls. Data on gender, age, histological type, TNM stage, metastatic status and the Lauren classification were collected from the medical record library of the hospital. This study was approved by the Ethics Committee of the 82nd hospital of the PLA, and informed consent was obtained from the patients in accordance with the Declaration of Helsinki.

Immunohistochemical staining. Immunohistochemical staining was carried out using a rabbit SP immunostaining kit (Zhongshan Goldenbridge Biotechnology, Beijing, China). Sections were dewaxed in xylene and dehydrated through a gradient concentration of alcohol. Then, sections were treated in a microwave for $10 \mathrm{~min}$ for antigen retrieval. After blocking the endogenous peroxidase and non-specific staining with $0.3 \%(\mathrm{v} / \mathrm{v})$ hydrogen peroxide and normal goat serum, the sections were incubated with anti-DBC1 antibody (1:100 dilution, Bethyl Lab, Montgomery, TX, USA) overnight at $4^{\circ} \mathrm{C}$. After washing with PBS, the sections were incubated with horseradish peroxidase (HRP)-conjugated biotinylated IgG for $30 \mathrm{~min}$, followed by washing with phosphate-buffered saline (PBS). The sections were visualized by diaminobenzidine (DAB) solution and counterstained with hematoxylin (both from Zhongshan Goldenbridge Biotechnology). The sections incubated with rabbit IgG instead of primary antibody were used as negative controls.

Staining evaluation. Immunohistochemical staining was examined by two independent pathologists who were blinded to the clinicopathological information. Each case was evaluated to estimate the intensity of cell staining and the percentage of positive tumor cells. The intensity of cell staining was graded according to the following scale: 0 (negative), 1 (weak), 2 (moderate) and 3 (strong). The extent of staining was evaluated by the percentage of positive tumor cells: 0 (negative), 1 (1-25\%), 2 (26-50\%), $3(51-75 \%)$ and 4 (76-100\%). For each sample, the score for intensity was multiplied by the score for extent of staining to provide a final score. Therefore, the expression of DBC1 was defined as: 0 (negative, -), 1-4 (low expression, +), 5-8 (moderate expression, ++), and 9-12 (high expression, +++$)$. For multiple lymph node metastases in a single case, an average immunohistochemical score was calculated to define the expression of DBC1 in metastatic lymph nodes.

Cell culture and transfection. Human MKN45 and MGC803 gastric cancer cell lines were cultured in modified Eagle's medium (MEM) supplemented with $10 \%$ fetal bovine serum, $100 \mathrm{U} / \mathrm{ml}$ penicillin, and $100 \mu \mathrm{g} / \mathrm{ml}$ streptomycin. The cells were maintained at $37^{\circ} \mathrm{C}$ in a humidified $5 \% \mathrm{CO}_{2}$ incubator. For transient transfection, the gastric cancer cells were transfected with lentivirus-mediated DBC1 (Lent-DBC1) or DBC1 shRNA (Lent-sh-DBC1) at a multiplicity of infection of 10 . The cells transfected with lentivirus vector encoding the green fluorescent protein were used as controls.

Anoikis analysis. After a 48-h transfection, the gastric cancer cells were collected and continuously cultured in plates precoated with Poly-HEMA for 48 h $(16,17)$. Subsequently, the cells were stained with Annexin V/PI and analyzed by flow cytometry.

Luciferase analysis. The gastric cancer cells were seeded in 6 -well plates at a concentration of $1.0 \times 10^{5} /$ well. After $24 \mathrm{~h}$, the cells were infected with lentivirus and treated with Bay 11-7082 $(10 \mu \mathrm{M})$ or PDTC $(50 \mu \mathrm{M}) 24 \mathrm{~h}$ later. After another $24 \mathrm{~h}$, cells were co-transfected with $1 \mu \mathrm{g}$ of NF- $\kappa \mathrm{B}$ luciferase reporter $\mathrm{pNF}-\kappa \mathrm{B}-\mathrm{luc} \mathrm{WT}$ and $50 \mathrm{ng}$ of Renilla luciferase plasmid phRL-TK (Promega, Madison, WI, USA) using Lipofectamine 2000 transfection reagent (Invitrogen, USA). Reporter activities were analyzed using the Promega dual luciferase assay kit (Promega) according to the manufacturer's instructions. The luciferase activity was normalized to the Renilla luciferase activity.

Western blot analysis. Total cell lysate was prepared in 1X SDS buffer. Proteins were separated by SDS-PAGE and transferred onto PDVF membranes. The membranes were then blotted with antibodies to DBC1 (Bethyl Lab), c-FLIP, bcl-xl and $\beta$-actin (Santa Cruz Biotechnology, Inc., Santa Cruz, CA, USA). Antigen-antibody complexes were visualized with enhanced chemiluminescence (Amersham Pharmacia Biotech, Piscataway, NJ, USA).

$R T$ - $q P C R$ analysis. The TaqMan stem-loop RT-PCR method was used to assess the expression of c-FLIP, bcl-xl and GAPDH with kits from Applied Biosystems (Foster City, USA). For relative expression levels, the $2(-\Delta \mathrm{Ct})$ method was used as previously described (18). Experiments were carried out in triplicate for each data point, and a data analysis was performed using Bio-Rad IQ software (Hercules, CA, USA).

Statistical analysis. Data are presented as means \pm SEM. The Chi-square test was used to compare the differences in the DBC1 expression level with various clinicopathological parameters in gastric cancer. Survival curves were plotted by the Kaplan-Meier method and the log-rank test was carried out to compare differences in survival. Statistical analyses were performed using SPSS 17.0 software (Chicago, IL, USA). $\mathrm{P}<0.05$ was considered statistically significant.

\section{Results}

Increased expression of $\mathrm{DBCl}$ is associated with lymph node metastasis in gastric adenocarcinoma. Immunohistochemistry was performed to detect the expression of DBC1 in 142 cases of gastric adenocarcinoma tissues and the corresponding adjacent non-tumor tissues. DBC1 was detected primarily in the nuclei of cancer cells (Fig. 1). High expression $(+++)$, moderate expression (++), low expression (+), and negative expression (-) of DBC1 were identified in 13, 32, 47 and 50 samples of the adenocarcinoma tissues, respectively, while in the adjacent nontumor tissues, only a few cells with weak staining for DBC1 were observed in two cases. We also assessed the potential relationship between DBC1 expression and clinical characteristics of gastric adenocarcinomas. As shown in Table I, the expression of DBC1 was significantly correlated with TNM stage $(\mathrm{P}<0.05)$ and lymph node metastasis $(\mathrm{P}<0.05)$. However, there was no significant correlation between $\mathrm{DBC} 1$ expression 
Table I. Correlation between DBC1 expression and clinical characteristics of gastric cancer.

\begin{tabular}{|c|c|c|c|c|c|c|}
\hline \multirow[b]{2}{*}{ Characteristics } & \multirow[b]{2}{*}{ No. of patients } & \multicolumn{4}{|c|}{ DBC1 staining } & \multirow[b]{2}{*}{ P-value } \\
\hline & & - & + & ++ & +++ & \\
\hline Age (years) & & & & & & 0.710 \\
\hline$\geq 60$ & 90 & 31 & 32 & 18 & 9 & \\
\hline$<60$ & 52 & 19 & 15 & 14 & 4 & \\
\hline Gender & & & & & & 0.944 \\
\hline Female & 51 & 17 & 18 & 12 & 4 & \\
\hline Male & 91 & 33 & 29 & 20 & 9 & \\
\hline TNM stage & & & & & & $0.021^{\mathrm{a}}$ \\
\hline I and II & 69 & 32 & 22 & 12 & 3 & \\
\hline III and IV & 73 & 18 & 25 & 20 & 10 & \\
\hline LN metastasis & & & & & & $0.017^{\mathrm{a}}$ \\
\hline Absence & 42 & 23 & 10 & 7 & 2 & \\
\hline Presence & 100 & 27 & 37 & 25 & 11 & \\
\hline Distant metastasis & & & & & & 0.363 \\
\hline Absence & 139 & 50 & 46 & 31 & 12 & \\
\hline Presence & 3 & 0 & 1 & 1 & 1 & \\
\hline Histological grade & & & & & & 0.279 \\
\hline Well-differentiated & 9 & 4 & 2 & 2 & 1 & \\
\hline Moderately differentiated & 81 & 33 & 29 & 14 & 5 & \\
\hline Poorly differentiated & 52 & 13 & 16 & 16 & 7 & \\
\hline Lauren classification & & & & & & 0.987 \\
\hline Intestinal & 60 & 21 & 20 & 14 & 5 & \\
\hline Diffuse & 70 & 26 & 22 & 15 & 7 & \\
\hline Mixed & 12 & 3 & 5 & 3 & 1 & \\
\hline
\end{tabular}

${ }^{\mathrm{a}} \mathrm{P}<0.05$.

and age, gender, distant metastasis, histological grade and the Lauren classification $(\mathrm{P}>0.05)$.

Given that DBC1 expression was significantly correlated with lymph node metastasis, we also detected the expression of DBC1 in lymph node metastasis and found that the expression level of DBC1 in the metastatic lymph nodes was concomitant with that in the primary gastric adenocarcinoma tissues (Linear correlation analysis for immunohistochemical scores, $\mathrm{P}<0.05)$. Moreover, in cases identified as low DBC1 expression, we found that the percentage of DBC1-positively expressed cancer cells in metastatic lymph nodes was markedly higher than that for the primary site $(\mathrm{P}<0.05$, Fig. 1C).

The relationship between DBC1 expression and survival was also analyzed. The mean survival times in patients with high expression $(+++)$, moderate expression $(++)$, low expression (+) and negative expression (-) of DBC1 were 27.5, 38.0, 40.7 and 44.6 months, respectively. The Kaplan-Meier analysis (Fig. 2) revealed that DBC1 expression was significantly correlated with a shorter overall survival time (log-rank, Chi-square $=8.551, \mathrm{P}<0.05)$.

DBC1 expression correlates with the ability of gastric cancer cells to resist anoikis. Resistance to anoikis has been consid- ered a hallmark of metastatic cancer cells, as it is required for anchorage-independent growth during tumor dissemination. Previous studies have identified that $\mathrm{DBC} 1$ is an important co-factor for the control of the IKK- $\beta / \mathrm{NF}-\kappa \mathrm{B}$ signaling pathway that regulates anoikis (7). Therefore, we hypothesized that $\mathrm{DBC} 1$ is involved in the metastasis of gastric cancer cells by mediating resistance to anoikis via IKK- $\beta / N F-\kappa B$ signal. We initially examined the effect of DBC1 expression on anoikis in gastric cancer cells. To achieve this, lentivirus-mediated DBC1 or DBC1 shRNA were transfected into MKN45 and MGC803 cells. As shown by western blot analysis in Fig. 3A, DBC1 protein levels in the MKN45 and MGC803 cells following transfection with lentivirus-mediated DBC1 were significantly increased compared with that of controls. As expected, in the MKN45 and MGC803 cells, the DBC1 upregulation resulted in a significant inhibition of the cell detachment-induced anoikis $(\mathrm{P}<0.05$, Fig. 3B). Concurrently, the specific downregulation of $\mathrm{DBC} 1$ expression by lentivirus-mediated $\mathrm{DBC} 1$ shRNA induced an increased sensitivity to the anoikis in MKN45 and MGC803 cells ( $\mathrm{P}<0.05$, Fig. 3A and B).

$I K K-\beta / N F-\kappa B$ signaling pathway is involved in the regulation of anoikis by DBCl in gastric cancer cells. In this study, 

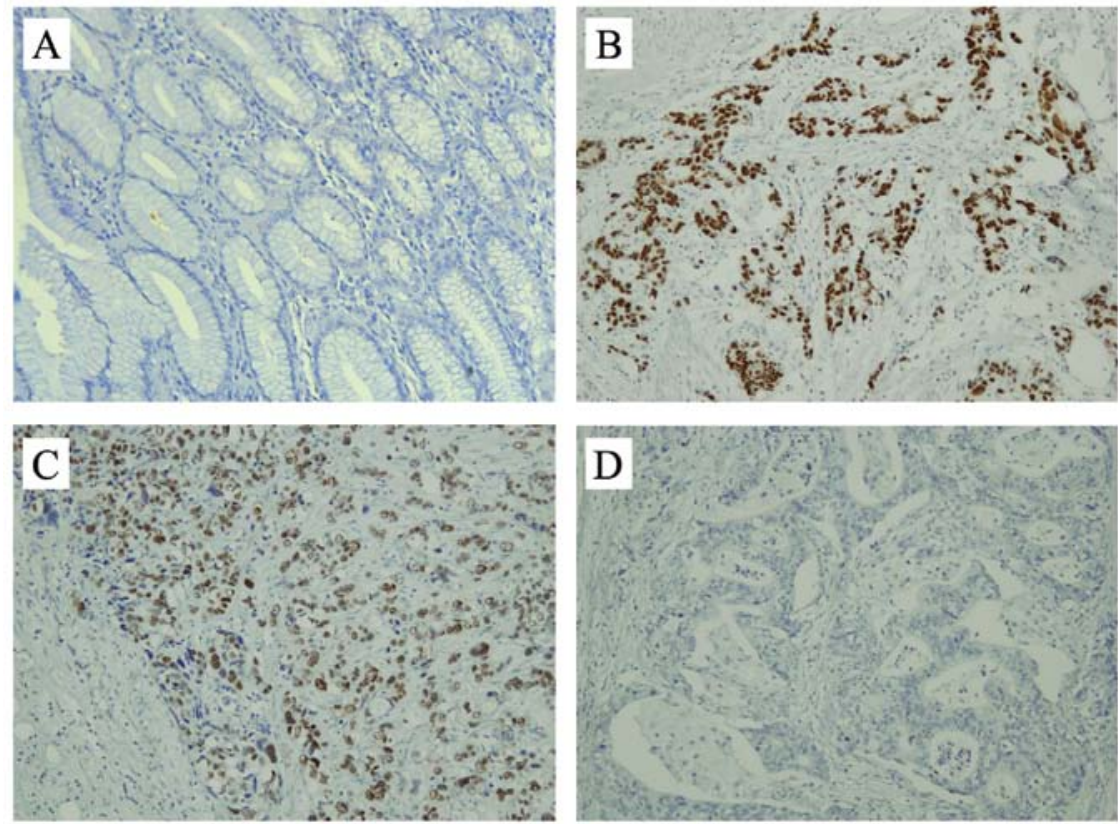

Figure 1. Immunohistochemical staining of DBC1 in gastric adenocarcinoma (magnification, $\mathrm{x} 100$ ). (A) Negative expression of DBC1 in adjacent non-tumor tissues. (B) Positive DBC1 staining in gastric adenocarcinoma tissue. (C) DBC1 expression in lymph node metastasis. (D) Negative control.

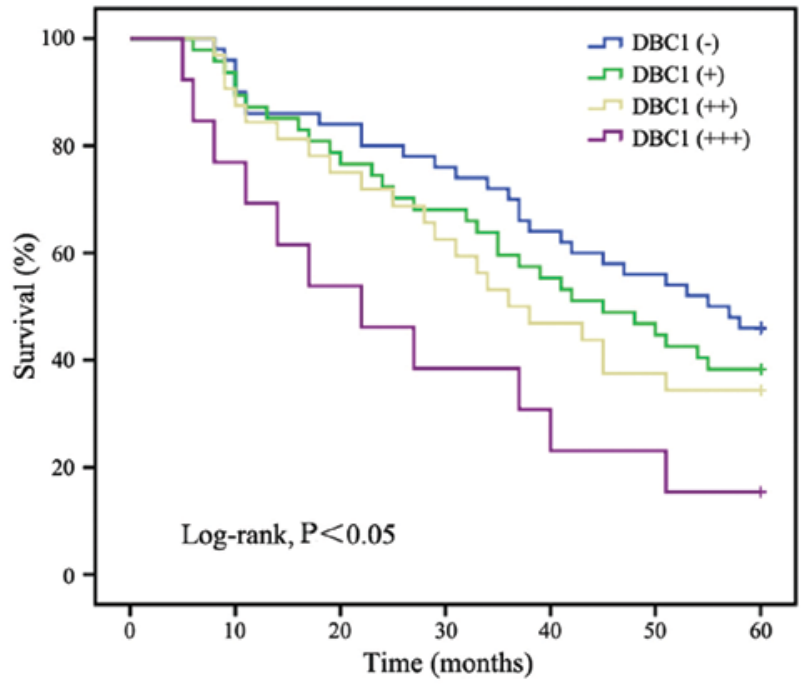

Figure 2. Kaplan-Meier survival curves in gastric cancer according to DBC1 staining. The mean follow-up period was 40.3 months (median, 44.0 months; range, 5-60 months). $\mathrm{P}<0.05$.

Bay 11-7082, a highly specific inhibitor of IKK- $\beta$ activity, and PDTC, a specific inhibitor of NF- $\mathrm{kB}$ activity, were used to assess the role of the IKK- $\beta / \mathrm{NF}-\mathrm{KB}$ signaling pathway in the regulation of anoikis by DBC1 (19,20). Fig. 4A shows that in DBC1 upregulated gastric cancer cells (MKN45 and MGC803), the levels of NF- $\kappa B$ activation following detachment were significantly higher than that of the control cells $(\mathrm{P}<0.05)$. However, we also observed that in gastric cancer cells cultured in normal cell plates, $\mathrm{DBC} 1$ upregulation did not obviously influence the activation of NF- $\kappa B(P>0.05)$. Fig. 4B shows that NF- $\mathrm{kB}$ activation was significantly inhibited in gastric cancer cells following detachment after exposure of
Bay 11-7082 or PDTC, and coincidently, the anoikis rates of gastric cancer cells were significantly increased. Fig. 4C shows that either Bay 11-7082 or PDTC reversed the increased anoikis resistance in DBC1-upregulated gastric cancer cells, which indicated that $\mathrm{DBC} 1$ contributed to the anoikis resistance by activating the IKK- $\beta / \mathrm{NF}-\kappa \mathrm{B}$ signaling pathway.

$D B C 1$ promotes anoikis resistance by regulating $N F-\kappa B$ mediated transcription. Among NF- $\mathrm{KB}$ target genes, c-FLIP and bcl-xl are particularly noted for their ability to regulate anoikis $(7,21,22)$. We examined the mRNA and protein expression changes of c-FLIP and bcl-xl in DBCl upregulated gastric cancer cells (MKN45 and MGC803). As shown in Fig. 5A and $\mathrm{B}$, the mRNA and protein expression levels of c-FLIP and bcl-xl were significantly increased in DBC1 upregulated gastric cancer cells following detachment. We also examined the effects of Bay 11-7082 and PDTC on the expression of c-FLIP and bcl-xl. As expected, after exposure of Bay 11-7082 or PDTC, the improved mRNA and protein expression of c-FLIP and bcl-xl were reversed in the DBC1 upregulated gastric cancer cells, further indicating that $\mathrm{DBC} 1$ promotes anoikis resistance by regulating NF- $\mathrm{KB}$-mediated transcription.

\section{Discussion}

DBC1 was first identified in 2002 by Hamaguchi et al (23). As a new transcriptional co-activator, $\mathrm{DBCl}$ exhibits its function by modulating the activities of various proteins. Currently, the role of $\mathrm{DBC} 1$ in cell survival remains controversial. On the one hand, DBC1 has been revealed to be able to directly bind to the catalytic domain of SIRT1 and decrease the deacetylase activity of SIRT1, thus inhibiting SIRT1-dependent cell survival $(12,13)$. On the other hand, DBC1 mediates endocrine-resistant breast cancer cell survival. It promotes 

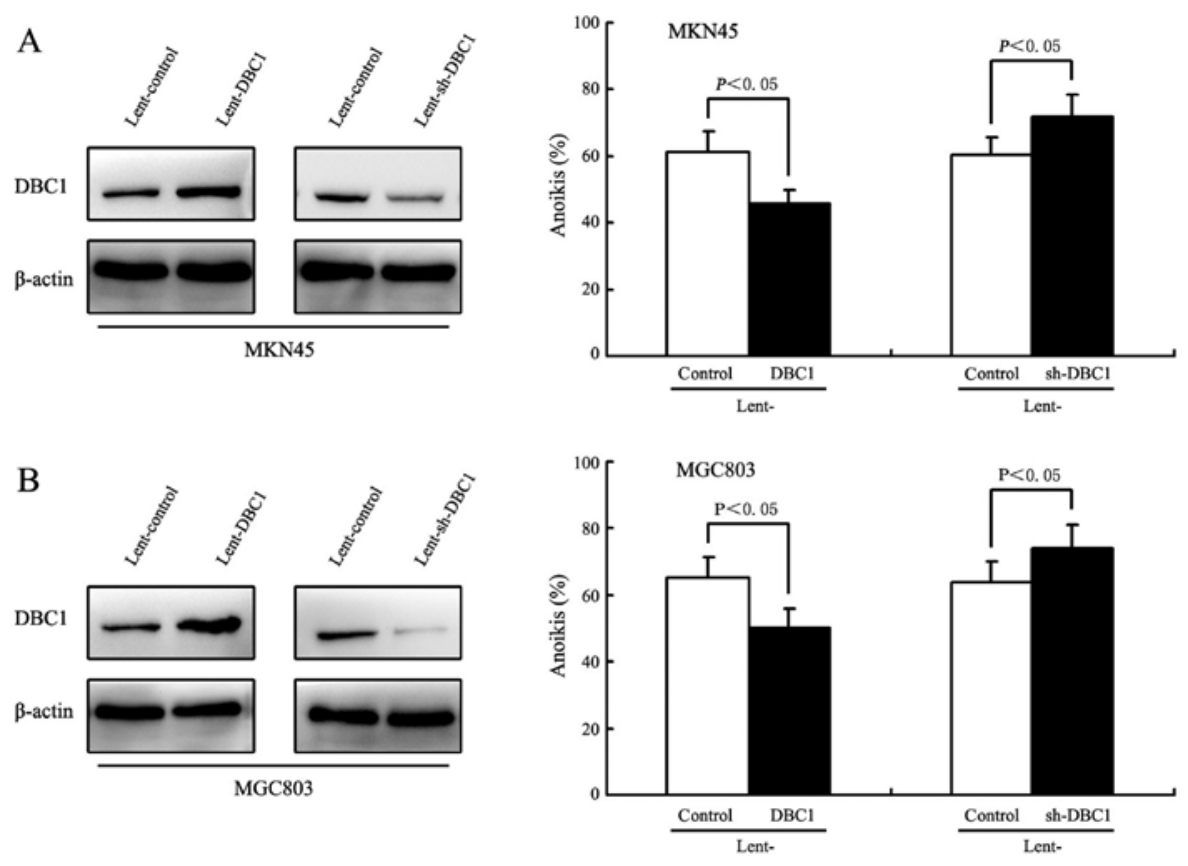

Figure 3. Effects of DBC1 expression on the sensitivity to anoikis in gastric cancer cells. (A) MKN45 and (B) MGC803 cells. Data are representative of five independent experiments.

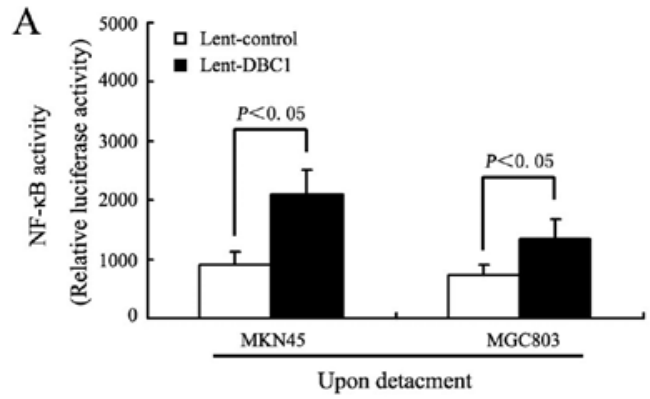

B

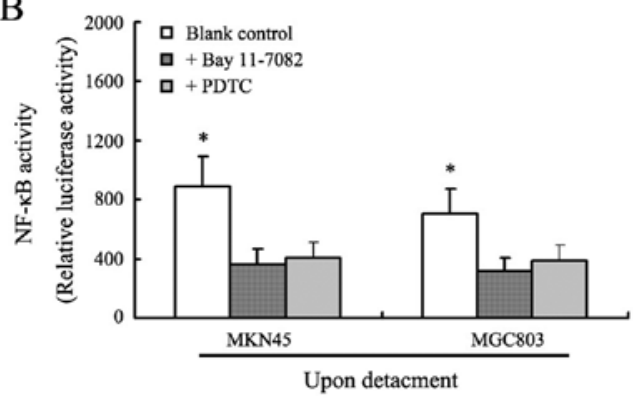

C

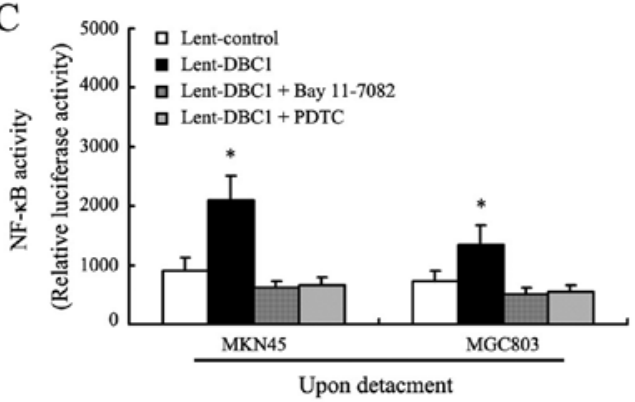

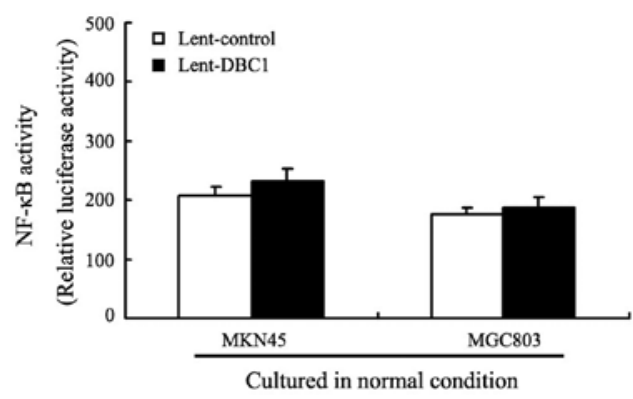
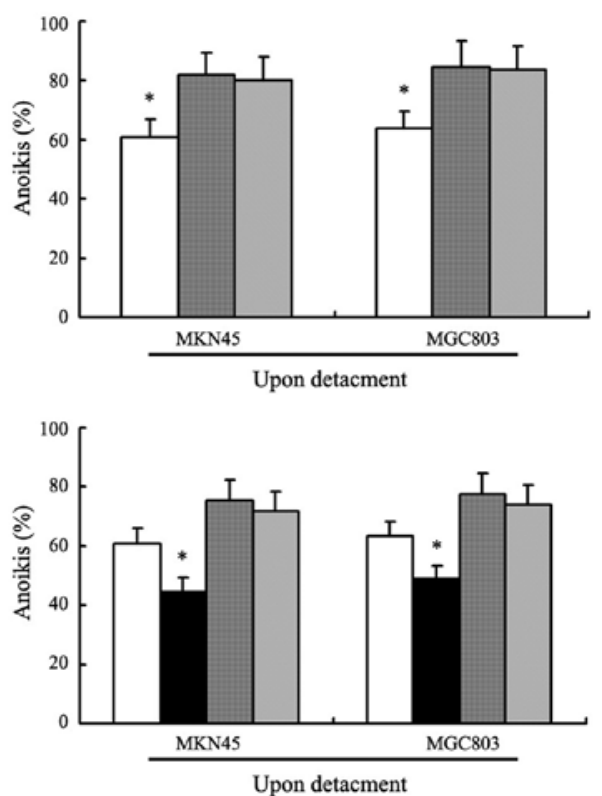

Figure 4. DBC1 regulates anoikis via the IKK- $\beta / \mathrm{NF}-\kappa \mathrm{B}$ signaling pathway. (A) Left panel: DBC1 increased the level of NF- $\mathrm{kB}$ activation following detachment in gastric cancer cells; right panel: $\mathrm{DBC1}$ did not increase the level of NF- $\mathrm{kB}$ activation in gastric cancer cells cultured in normal condition. (B) Inhibition of

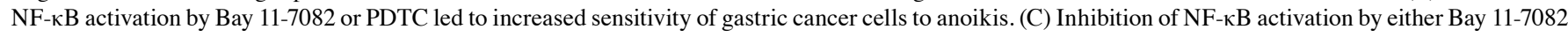
or PDTC reversed the influence of DBC1 upregulation in the sensitivity of gastric cancer cells to anoikis. Data are representative of five independent experiments. ${ }^{*} \mathrm{P}<0.05$ vs. other groups. 

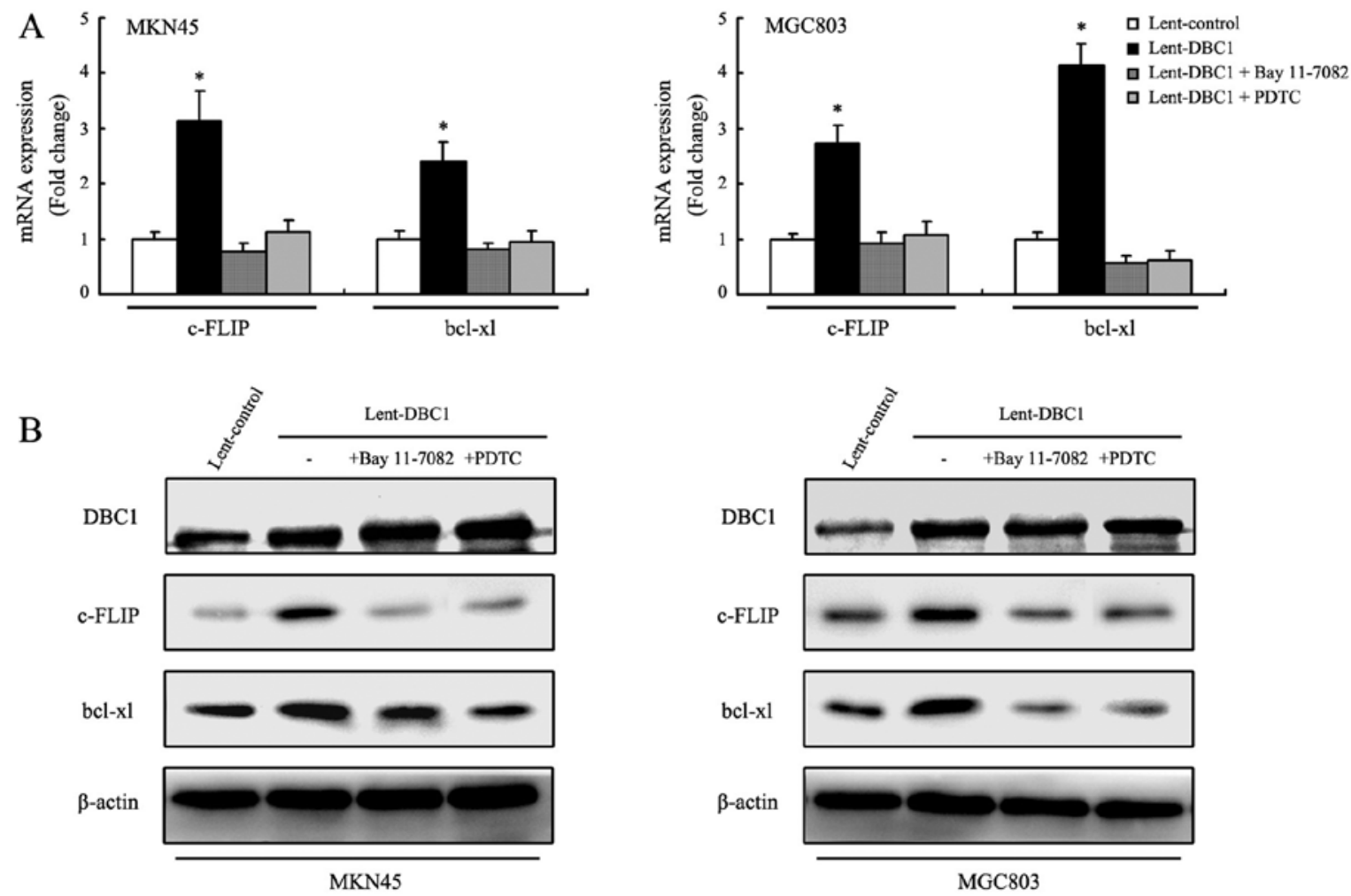

Figure 5. DBC1 affects the expression of NF- $\mathrm{kB}$ target genes in gastric cancer cells. (A) The mRNA and (B) protein expression levels of c-FLIP and bcl-xl. Data are representative of five independent experiments. ${ }^{*}<0.05$, vs. other groups.

estrogen-independent proliferation and inhibits estrogen-independent apoptosis in estrogen receptor $\alpha$ positive breast cancer cells $(24,25)$. DBC1 also represses the transcription of BRCA1 and inhibits its tumor-suppressor activity (14). Several studies also reported that $\mathrm{DBC} 1$ modulates cell growth by regulating the transcriptional activity of retinoic acid receptor $\alpha$ and androgen receptor in breast and prostate cancer cells (26-28). The abovementioned findings indicated that DBC1 may act as either a tumor promoter or a tumor suppressor in tumorigenesis, depending on the cell context and type of tumor.

Although DBC1 was initially termed as deleted in breast cancer 1 , it was subsequenlty found to be overexpressed in breast cancer tissues in comparison with corresponding matched normal tissues, and that overexpression was correlated with clinicopathological factors, especially metastasis, and poor prognosis $(10,11)$. DBC1 was then found to be overexpressed in various human cancers including esophageal cancer, colorectal cancer, soft tissue sarcomas and lymphoma $(8,9,29,30)$. With regards to gastric cancer, Kang et al and Cha et al showed that DBC1 was overexpressed in gastric cancer tissues and could be used as a prognostic indicator for gastric cancer patients $(31,32)$. In the present study, we found that $\mathrm{DBC} 1$ was significantly upregulated in gastric adenocarcinoma patients and this expression was significantly correlated with TNM stage and lymph node metastasis. Our results also support that $\mathrm{DBC} 1$ is a prognostic factor that is associated with poor prognosis in gastric cancer. In addition, we examined the expression of DBC1 in metastatic lymph nodes and found a higher expression that in the primary gastric cancer tissues, further indicating that $\mathrm{DBC} 1$ may play an important role in gastric cancer metastasis.
Anoikis, a special form of apoptosis occurring when cells detach from the extracellular matrix, is a critical mechanism in maintaining tissue homeostasis and development. Anoikisresistance has been considered as a hallmark of metastatic cancer cells, especially because the anchorage-independent growth of cancer cells is a classic characteristic of different types of human malignancies (33). Among the signaling and transcription factor pathways involved in regulating anoikis, inflammatory-response transcription factor NF- $\mathrm{kB}$ is notable because it links anoikis with inflammatory signaling between and within cells $(34,35)$. Recently, Park et al reported that DBC1 suppresses anoikis in both normal epithelial and cancer cells (breast cancer MCF10a cells) by regulating the IKK- $\beta / \mathrm{NF}-\kappa \mathrm{B}$ signaling pathway. DBC1 may be conceptualized as a co-factor for IKK- $\beta$ that stimulates its kinase activity on relA (S536), promoting the transcriptional activation of NF- $\mathrm{KB}$ target genes such as c-FLIP and bcl-xl, which enhance anoikis resistance (7). Using gene transfection assays, we showed that $\mathrm{DBC} 1$ expression correlates with the ability of anoikis resistance in gastric cancer cells. Furthermore, by using Bay 11-7082 and PDTC, we demonstrated that the IKK- $\beta / N F-\kappa B$ signaling pathway is involved in the regulation of anoikis resistance by DBC1 in gastric cancer cells. Combined with the immunohistochemical results, we suggest that there is a subset of gastric cancer cells with a high DBC1 expression that can survive the detachment process for enhanced NF- $\mathrm{BB}$ activation, subsequently leading to metastasis.

In summary, our study has demonstrated that $\mathrm{DBC} 1$ is overexpressed in gastric cancer and associated with poor prognosis. Our study also provides experimental evidence that $\mathrm{DBC} 1$ promotes anoikis resistance in gastric cancer cells 
by regulating $N F-\kappa B$ activity, raising the possibility of using $\mathrm{DBC} 1$ as a new therapeutic target for preventing metastasis.

\section{References}

1. Lin JT: Screening of gastric cancer: Who, when, and how. Clin Gastroenterol Hepatol 12: 135-138, 2014.

2. Ferlay J, Shin HR, Bray F, Forman D, Mathers C and Parkin DM: Estimates of worldwide burden of cancer in 2008: GLOBOCAN 2008. Int J Cancer 127: 2893-2917, 2010.

3. Kim YN, Koo KH, Sung JY, Yun UJ and Kim H: Anoikis resistance: An essential prerequisite for tumor metastasis. Int J Cell Biol 2012: 306879, 2012.

4. Tan K, Goldstein D, Crowe P and Yang JL: Uncovering a key to the process of metastasis in human cancers: A review of critical regulators of anoikis. J Cancer Res Clin Oncol 139: 1795-1805 2013

5. Paoli P, Giannoni E and Chiarugi P: Anoikis molecular pathways and its role in cancer progression. Biochim Biophys Acta 1833 3481-3498, 2013

6. Zannini L, Buscemi G, Kim JE, Fontanella E and Delia D: DBC1 phosphorylation by ATM/ATR inhibits SIRT1 deacetylase in response to DNA damage. J Mol Cell Biol 4: 294-303, 2012.

7. Park SH, Riley P IV and Frisch SM: Regulation of anoikis by deleted in breast cancer-1 (DBC1) through NF- $\kappa \mathrm{B}$. Apoptosis 18: 949-962, 2013

8. Zhang Y, Gu Y, Sha S, Kong X, Zhu H, Xu B, Li Y and Wu K: $\mathrm{DBC} 1$ is over-expressed and associated with poor prognosis in colorectal cancer. Int J Clin Oncol 19: 106-112, 2014.

9. Kim SH, Kim JH, Yu EJ, Lee KW and Park CK: The overexpression of DBC1 in esophageal squamous cell carcinoma correlates with poor prognosis. Histol Histopathol 27: 49-58, 2012.

10. Lee H, Kim KR, Noh SJ, Park HS, Kwon KS, Park BH, Jung SH Youn HJ, Lee BK, Chung MJ, et al: Expression of DBC1 and SIRT1 is associated with poor prognosis for breast carcinoma. Hum Pathol 42: 204-213, 2011.

11. Hiraike H, Wada-Hiraike O, Nakagawa S, Saji S, Maeda D, Miyamoto Y, Sone K, Tanikawa M, Oda K, Nakagawa K, et al: Expression of DBC1 is associated with nuclear grade and HER2 expression in breast cancer. Exp Ther Med 2: 1105-1109, 2011.

12. Zhao W, Kruse JP, Tang Y, Jung SY, Qin J and Gu W: Negative regulation of the deacetylase SIRT1 by DBC1. Nature 451: 587-590, 2008.

13. Kim JE, Chen J and Lou Z: DBC1 is a negative regulator of SIRT1. Nature 451: 583-586, 2008

14. Hiraike H, Wada-Hiraike O, Nakagawa S, Koyama S, Miyamoto Y, Sone K, Tanikawa M, Tsuruga T, Nagasaka K, Matsumoto $\mathrm{Y}$, et al: Identification of $\mathrm{DBC1}$ as a transcriptional repressor for BRCA1. Br J Cancer 102: 1061-1067, 2010.

15. Koyama S, Wada-Hiraike O, NakagawaS, Tanikawa M,Hiraike $H$ Miyamoto Y, Sone K, Oda K, Fukuhara H, Nakagawa K, et al: Repression of estrogen receptor beta function by putative tumor suppressor DBC1. Biochem Biophys Res Commun 392: 357-362, 2010.

16. Schafer ZT, Grassian AR, Song L, Jiang Z, Gerhart-Hines Z, Irie HY, Gao S, Puigserver P and Brugge JS: Antioxidant and oncogene rescue of metabolic defects caused by loss of matrix attachment. Nature 461: 109-113, 2009.

17. Zhang YF, Zhang AR, Zhang BC, Rao ZG, Gao JF, Lv MH, Wu YY, Wang SM, Wang RQ and Fang DC: MiR-26a regulates cell cycle and anoikis of human esophageal adenocarcinoma cells through Rb1-E2F1 signaling pathway. Mol Biol Rep 40: 1711-1720, 2013.
18. Livak KJ and Schmittgen TD: Analysis of relative gene expression data using real-time quantitative PCR and the 2(-Delta Delta $\mathrm{C}(\mathrm{T})$ ) method. Methods 25: 402-408, 2001

19. Rauert-Wunderlich H, Siegmund D, Maier E, Giner T, Bargou RC, Wajant $\mathrm{H}$ and Stühmer T: The IKK inhibitor Bay 11-7082 induces cell death independent from inhibition of activation of $\mathrm{NF \kappa B}$ transcription factors. PLoS One 8: e59292, 2013.

20. Liu SF, Ye X and Malik AB: Inhibition of NF-kappaB activation by pyrrolidine dithiocarbamate prevents in vivo expression of proinflammatory genes. Circulation 100: 1330-1337, 1999.

21. Oztürk S, Schleich K and Lavrik IN: Cellular FLICE-like inhibitory proteins (c-FLIPs): Fine-tuners of life and death decisions. Exp Cell Res 318: 1324-1331, 2012.

22. Luqman S and Pezzuto JM: NFkappaB: A promising target for natural products in cancer chemoprevention. Phytother Res 24: 949-963, 2010.

23. Hamaguchi M, Meth JL, von Klitzing C, Wei W, Esposito D, Rodgers L, Walsh T, Welcsh P, King MC and Wigler MH: DBC2, a candidate for a tumor suppressor gene involved in breast cancer. Proc Natl Acad Sci USA 99: 13647-13652, 2002.

24. Trauernicht AM, Kim SJ, Kim NH, Clarke R and Boyer TG: DBC-1 mediates endocrine resistant breast cancer cell survival. Cell Cycle 9: 1218-1219, 2010.

25. Trauernicht AM, Kim SJ, Kim NH and Boyer TG: Modulation of estrogen receptor alpha protein level and survival function by DBC-1. Mol Endocrinol 21: 1526-1536, 2007.

26. Kim JE and Sung S: Deleted in breast cancer 1 (DBC1) is a dynamically regulated protein. Neoplasma 57: 365-368, 2010.

27. Garapaty S, Xu CF, Trojer P, Mahajan MA, Neubert TA and Samuels HH: Identification and characterization of a novel nuclear protein complex involved in nuclear hormone receptormediated gene regulation. J Biol Chem 284: 7542-7552, 2009.

28. Fu J, Jiang J, Li J, Wang S, Shi G, Feng Q, White E, Qin J and Wong J: Deleted in breast cancer 1, a novel androgen receptor (AR) coactivator that promotes AR DNA-binding activity. J Biol Chem 284: 6832-6840, 2009

29. Kim JR, Moon YJ, Kwon KS, Bae JS, Wagle S, Yu TK, Kim KM, Park HS, Lee JH, Moon WS, et al: Expression of SIRT1 and $\mathrm{DBC} 1$ is associated with poor prognosis of soft tissue sarcomas. PLoS One 8: e74738, 2013.

30. Park HS, Bae JS, Noh SJ, Kim KM, Lee H, Moon WS, Chung MJ, Kang MJ, Lee DG and Jang KY: Expression of DBC1 and Androgen Receptor Predict Poor Prognosis in Diffuse Large B Cell Lymphoma. Transl Oncol 6: 370-381, 2013.

31. Kang Y, Jung WY, Lee H, Lee E, Kim A and Kim BH: Expression of SIRT1 and DBC1 in gastric adenocarcinoma. Korean J Pathol 46: 523-531, 2012.

32. Cha EJ, Noh SJ, Kwon KS, Kim CY, Park BH, Park HS, Lee H, Chung MJ, Kang MJ, Lee DG, et al: Expression of DBC1 and SIRT1 is associated with poor prognosis of gastric carcinoma. Clin Cancer Res 15: 4453-4459, 2009.

33. Guadamillas MC, Cerezo A and Del Pozo MA: Overcoming anoikis-pathways to anchorage-independent growth in cancer. J Cell Sci 124: 3189-3197, 2011

34. Aggarwal BB and Sung B: NF- $\kappa B$ in cancer: A matter of life and death. Cancer Discov 1: 469-471, 2011.

35. DiDonato JA, Mercurio F and Karin M: NF- $\kappa B$ and the link between inflammation and cancer. Immunol Rev 246: 379-400, 2012. 